Article

\title{
Information Needs for a Purchase of Fairtrade Coffee
}

\section{Rosa Schleenbecker and Ulrich Hamm *}

Department of Agricultural and Food Marketing, University of Kassel, Witzenhausen 37213, Germany; E-Mail: rosa.schleenbecker@gmx.de

* Author to whom correspondence should be addressed; E-Mail: hamm@uni-kassel.de; Tel.: +49-5542-98-1285; Fax: +49-5542-98-1286.

Academic Editor: Marc A. Rosen

Received: 12 February 2015 / Accepted: 22 April 2015 / Published: 13 May 2015

\begin{abstract}
This research investigates what information German Fairtrade coffee consumers search for during pre-purchase information seeking and to what extent information is retrieved. Furthermore, the sequence of the information search as well as the degree of cognitive involvement is highlighted. The role of labeling, the importance of additional ethical information and its quality in terms of concreteness as well as the importance of product price and organic origin are addressed. A set of information relevant to Fairtrade consumers was tested by means of the Information Display Matrix (IDM) method with 389 Fairtrade consumers. Results show that prior to purchase, information on product packages plays an important role and is retrieved rather extensively, but search strategies that reduce the information processing effort are applied as well. Furthermore, general information is preferred over specific information. Results of two regression analyses indicate that purchase decisions are related to search behavior variables rather than to socio-demographic variables and purchase motives. In order to match product information with consumers' needs, marketers should offer information that is reduced to the central aspects of Fairtrade.
\end{abstract}

Keywords: consumer behavior; decision making; heuristics; decision strategies; ethical consumerism; Information Display Matrix; Fairtrade 


\section{Introduction}

An increase in societal concern regarding the ethical aspects of food production has been identified over the past several years [1-6]. This concern is also reflected in consumption patterns regarding manifold products with an additional "ethical" benefit (referred to as "ethical products"). These are, for example, products which are produced following organic production guidelines such as organic products, animal products which are produced following higher animal welfare standards or Fairtrade products. Fairtrade products are understood to be products that ensure producers from developing countries get "a better deal and improved terms of trade", such as minimum prices and the absence of forced labor and child labor [7]. The category which identifies Fairtrade products is not legally defined and contains many different standards. The private Transfair standard is the most prominent one.

Fairtrade products are niche products that have successfully entered the mainstream distribution channels [8-10]. This means that nowadays, Fairtrade products in Europe are not only found in specialized "world" shops, their traditional sales channel, but are also available at conventional food retailing [11]. Since 2010, Fairtrade products have gained high growth rates in sales. Between 2008 and 2013, worldwide turnover grew about 90\% [12]. Big food suppliers such as Starbucks, Nestlé and Cadbury increasingly source their raw material from Fairtrade indicating that these products are not only societally accepted, but have also gained market importance.

However, Fairtrade marketing faces the problem that consumers cannot verify the Fairtrade product attributes by themselves because the Fairtrade quality of the product cannot be ascertained just by examining the product. Fairtrade is a process quality which can only be verified in the production process. The products, consequently, are so-called "credence goods" due to the information asymmetry between consumers and traders [13]. Information is decisive in order to create the trust needed. Signaling is a method to reduce information asymmetry through lending credence to the underlying information by offering information on the credence characteristics [14]. However, the information given through signaling has to be adapted to consumers' needs in order to avoid information overload. As de Pelsmacker et al. [15] state, it is the lack of "good" information which puts consumers off purchasing Fairtrade products. However, so far, no research has been published on the topic of which information, in terms of content and quantity, is favored by Fairtrade consumers. A credible label can serve as a means to close the information gap and build up credibility by offering information in a condensed manner based on a certification process. De Pelsmacker and Janssens [16] state that a Fairtrade label can be a strong incentive to buy such a product.

Hence, the goal of the research project was to identify Fairtrade consumers' information needs regarding the extent and content of information search on Fairtrade product features. This also includes an examination of the role of Fairtrade labeling. Furthermore, this contribution will analyze the participants' approach to the information search. Thus, marketers can provide product information in conformity with the information needs and information processing capacities of Fairtrade consumers.

Purchase experiments based on the Information Display Matrix method are used to examine the research questions. An analysis of Fairtrade consumers' information search extent, content and method by means of a purchase experiment is novel and has not been performed to this extent before. The results are used in order to deduct marketing implications with regard to the question of how much and which 
information should be displayed when marketing Fairtrade products and, in which way information should be displayed.

This paper will firstly shed light on the theoretical background of decision making and the role of information. In the following, the applied methodology will be explained including a description of the research design and the sample. Subsequently, the results are discussed. Next, research limitations are explained and suggestions for further research are presented. Finally, implications both for marketing and consumer protection are given.

\section{Theoretical Background: Decision Making and the Role of Information}

\subsection{Decision Making}

Decision making is primarily seen as a process. Structural models are commonly used in order to schematically display decision making. The model used by Engel et al. contains the core ideas that have been reproduced by many other authors [14,17]. The first step is the recognition of a need, followed by information search. In the subsequent step, different alternatives are evaluated before the actual purchase decision is performed. Engel et al. also display the post-purchase-behavior [18] in which information search and uptake are important aspects $[14,17,19]$; however these were not considered in this research. The information search behavior is the experimentally observable phenomenon that permits inferences about information processing strategies [20-23]. During information processing, the available product alternatives are judged and compared. Criteria are then compiled based on the information that was gathered earlier. Since new information can be gathered and judged subsequently, the phases of information uptake and processing are closely related [24]. Alternatives are compared, criteria developed, and judgments made. However, the process is empirically unobservable. Since the information search allows for inferences on information processing, the information search as the observable phenomenon is used to draw conclusions on the purchase decision.

\subsection{Information Search Strategies}

In order to access the relevant information, different methods or strategies of information search are used. As Payne et al. [25] pointed out, strategies derive from the consideration of all alternatives including the retrieval of all information and subsequent trade-offs between information units to simple and quick rule-of-thumb techniques. Human decision making often does not match the criteria of rational decision making, which implies the consideration of all information and making of trade-offs. Therefore, so-called heuristics are used [17]. Heuristics are resource-efficient shortcuts in decision making. Following Payne et al. [25], heuristics are a cognitive response to the fact that only a reduced quantity of information can be taken in and processed. The application of heuristics implies a targeted search and trade-offs are avoided [25]. Heuristics are considered a means for avoiding information overload. At the same time, heuristics can also produce valuable results in less time and with less cognitive effort. Therefore, heuristics are cost efficient and allow for somewhat rapid judgments and decisions [26]. Hence, the interpretation of information search strategies provides important clues on the information processing with respect to the extent of cognitive effort. 
Within the method of information search, order and frequency are important indicators: both give insights into the importance of the information units. Important product attributes are retrieved more often and earlier [27,28]. The intensity of information retrieval, however, should be interpreted with caution since this repeated information retrieval can, beyond the fact that the person has a high interest level in the information, also be because the person has trouble memorizing the information and therefore has to retrieve it repeatedly [27].

Information search strategies can be classified using the following elementary criteria: strategies are either compensatory or non-compensatory, which means that a trade-off between attributes is either performed or not. Compensatory approaches are cognitively more demanding due to the trade-offs made. Furthermore, information search is performed either attribute-wise or alternative-wise. If a consumer uses an attribute-based approach, the attributes of an alternative are regarded in a sequence. If all specifications of an attribute are regarded one after the other, an alternative-wise approach is applied. Attribute-wise approaches are considered cognitively less burdening [29].

From a marketing perspective, the analysis of information search strategies is relevant since product and communication policy can be modified according to the importance of single attributes. Furthermore, the extent of the marketing message can be adapted to consumers' preferences, whereas the product and communication policy can be adjusted to the preference for either alternative-wise or attribute-wise information search. Additionally, if strategies are applied which focus on single attributes, those attributes should be addressed as well.

\section{Methodology: Information Display Matrix (IDM) Experiments}

The empirical survey was based on IDM experiments that were embedded into a computer-based questionnaire. The IDM is a quantitative research method that permits the analysis of consumers' information search and purchase decision behavior. Information is displayed in a matrix scheme and can be accessed by opening the fields of the matrix.

In the present study, the information was offered in a matrix with different products and general product attributes, in columns and rows, respectively (see Figure 1). The combination of the products and the attributes resulted in the fields of the matrix. These fields contained more detailed information ("arguments") on the product attributes. The information fields were initially covered and participants could only access them by opening the fields. This is graphically displayed in Figure 2. Each field was covered again after the participants viewed it. Participants could also make note of interesting information fields by marking them, much like information search in online shops. Finally, after having collected all the information needed, participants made a purchase decision. The IDM experiment was, as is common nowadays, computer based; therefore, the information fields could be opened by clicking on the field with a computer mouse. In the present experiment, the number of fields that participants could open was not limited and repeated access to fields was possible. The computer recorded the whole process of information accession. Thus, amount, content and sequence of information search as well as the final purchase decision could be analyzed. By collecting data on the information search process, conclusions on the information processing behavior could be drawn: the IDM application was equipped with a tool that visualized the information search paths: The sequence of information search was registered by the computer and could be displayed graphically by showing each step in the information uptake process. 
The graphic information was subsequently assigned to information search strategies which were described by e.g., Payne et al. [25].

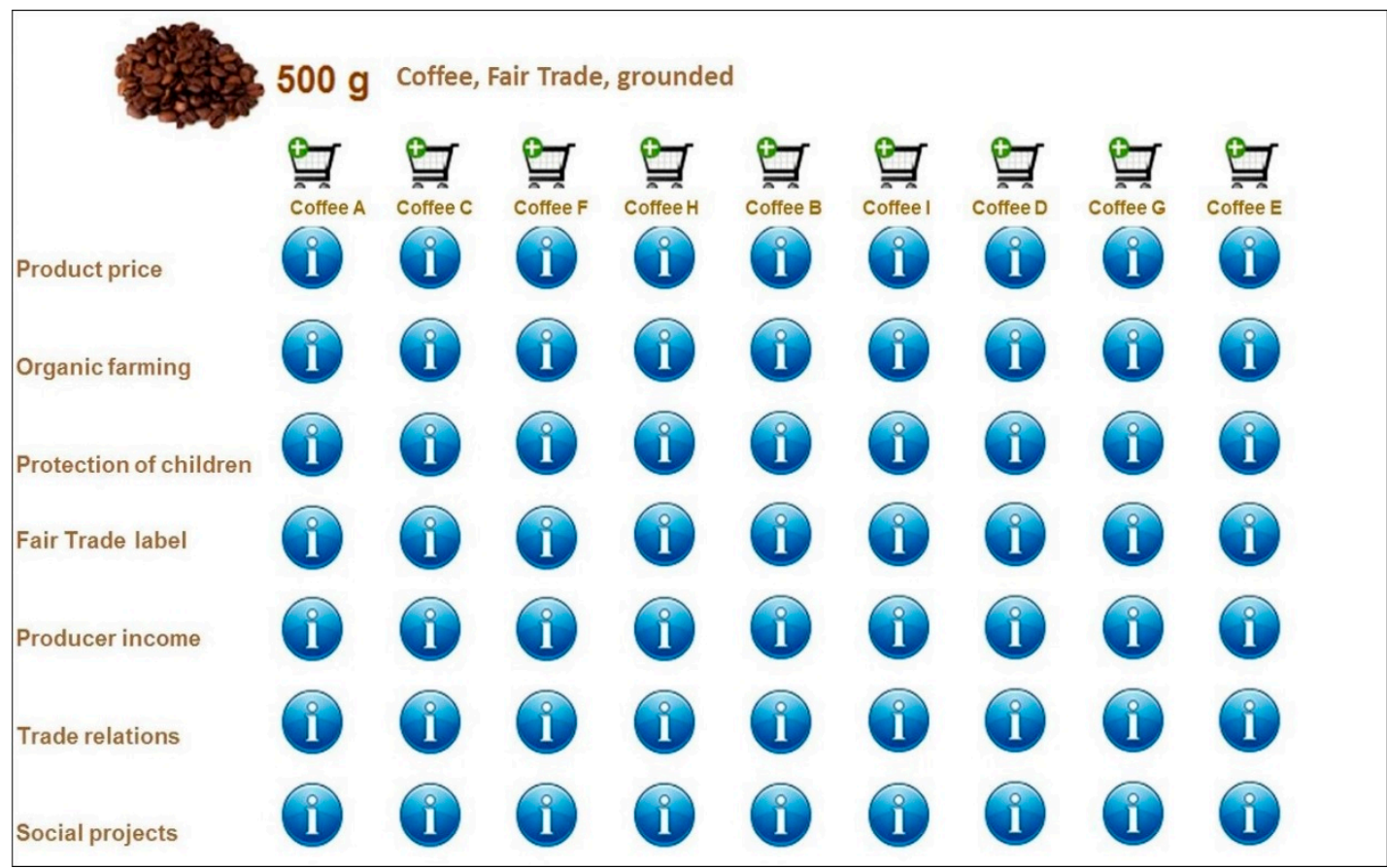

Figure 1. Screenshot of IDM. Source: Authors' own illustration.

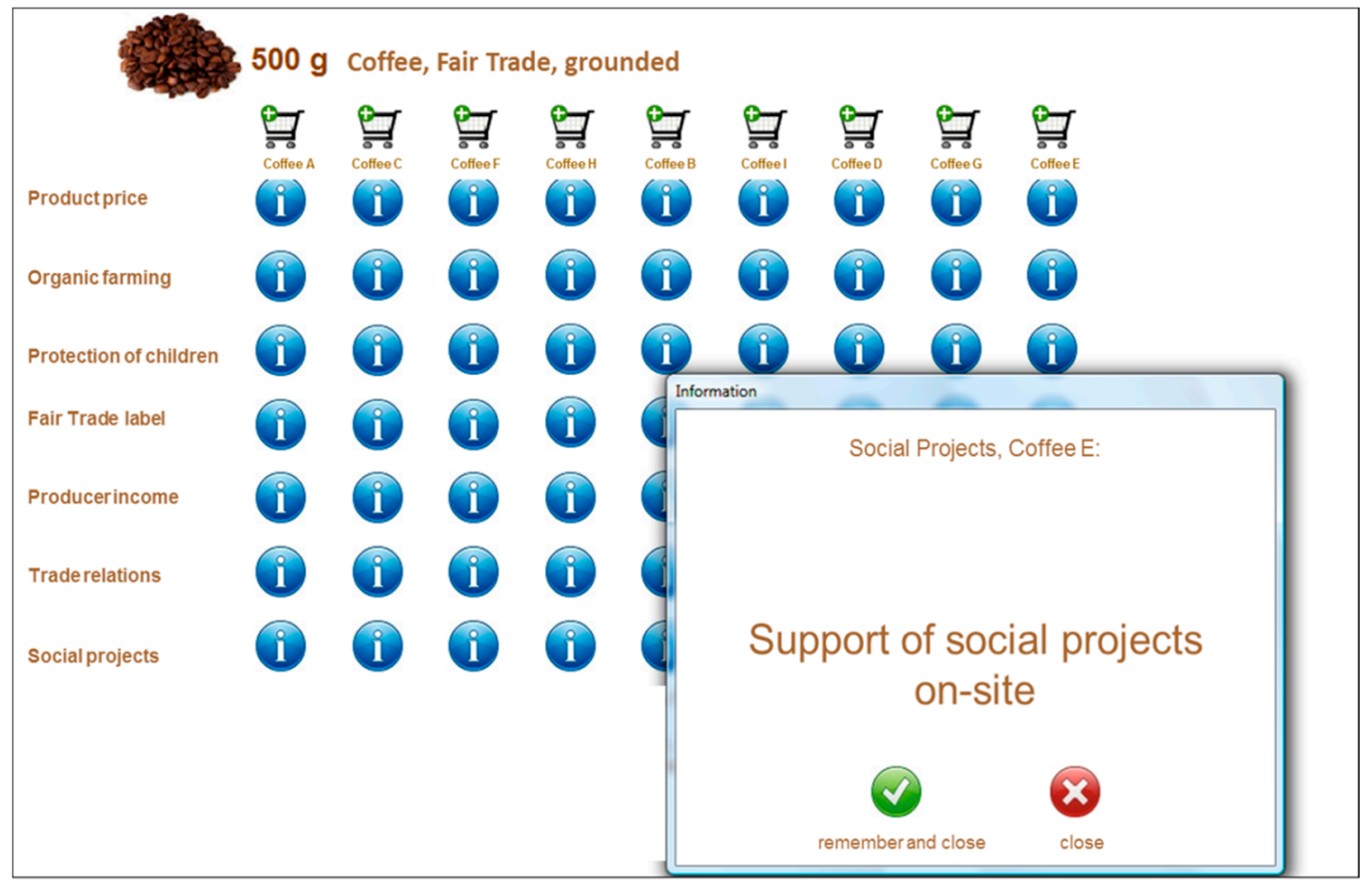

Figure 2. Screenshot of IDM with opened field. Source: Authors' own illustration.

The IDM method has several advantages compared to direct inquiries when the objective is to elaborate information search behavior. The application of the IDM minimizes the bias between actual and indicated behavior [30,31] due to the interaction with a computer instead of a person. Inquiries on ethical consumption are especially sensitive to misreporting due to a social desirability bias. Moreover, 
participants' information preferences were not based on reports regarding the remembered information uptake but surveyed in an experiment. In addition, the final purchase decision was simulated as binding, as participants were told that they had to pay for the selected product using the allowance $(€ 5)$ they received for participating. Furthermore, the experiments were conducted in a real shopping environment in order to minimize the implications of an artificial experimental situation while still having the advantage of controlled circumstances. The graphical design of the IDM was inspired by that of online shops in order to raise participants' familiarity with the issue. As prior research has indicated, the IDM is a suitable method for identifying consumer information search behavior when purchasing ethical products, especially since today's consumers are familiar with diagrammed information presentation due to online shops and product test magazines [32,33]. Furthermore, research has proven that the IDM is suitable to the analysis of products where a conscious and targeted information uptake is necessary $[28,34]$.

\section{Research Design and Sample Description}

\subsection{Research Design}

In this study, coffee was chosen as an exemplary Fairtrade product since coffee is the most important Fairtrade product in Germany [35]. The survey was conducted in 2011 in five retail stores that sold Fairtrade coffee in two German cities in order to embed the purchase experiments into a realistic setting. Two conventional supermarkets, two world shops and one organic food shop were included. In order to avoid interviewer biases, customers of those markets were randomly approached, i.e., every third passerby or every person in the less frequented shops, respectively, was asked to participate. If people agreed to participate, they were screened according to the criteria of Fairtrade product purchase on an at least occasional basis. Furthermore, to assure that the participants knew Fairtrade products, they were asked how they identified those products. If they could correctly explain how to identify Fairtrade products, they were asked to participate in the survey.

In the next step, participants were informed of their incentive of five euros which they could use for the coffee purchase in the experiment. They were then introduced to the IDM experiment with the help of an exemplary decision task, a purchase decision for yoghurt, before the actual experiment started. Then, participants could choose between nine different coffee products and were told that they should choose one of them, put it into the virtual shopping basket, and make a binding purchase decision. The nine different products were equipped with different information on the Fairtrade label, the production method (organic or conventional), the product price and additional information on the Fairtrade attributes, such as "protection of children" (confronting child labor), coffee producers' income, trade relations (such as a guaranteed purchase of the harvest) and social projects (such as the establishment of a health center) (cp. Table 1). Since there was hardly any information on which Fairtrade attributes are crucial to Fairtrade consumers, three focus group discussions were conducted as a pre-survey prior to this survey. In all, 27 German Fairtrade consumers (predominantly infrequent buyers) were surveyed regarding their Fairtrade purchase and information search behavior. The seven attributes were chosen based on the results of the focus group discussions, on literature and on information furnished by Fairtrade marketers. The specific information on the general attributes which was hidden behind the information fields varied in different ways: different prices ranging from $€ 4.99$ to $€ 6.49$ were given, 
according to the quality of information of the product. Label information was either given as the-at least in Germany-well-known Transfair label or a fake label ("FairVision") which did not exist on the real market. As production method, participants could choose between organic or conventional products, with organic products displaying the German governmental label and conventional products for which no information was given on the production method. Information on further ethical attributes varied in three ways: either the information was given in a precise manner (e.g., "fair trade conditions for the producers"), in an imprecise manner (e.g., "guaranteed purchase of harvest for two years") or the field contained no information. Figure 3 offers an overview of the general product design.

Table 1. Schematic overview over product design.

\begin{tabular}{|c|c|c|c|c|c|c|c|c|c|}
\hline & product $\mathbf{A}$ & product B & product $\mathrm{C}$ & product D & product $\mathbf{E}$ & product $F$ & product $G$ & product $\mathbf{H}$ & product I \\
\hline price & $€ 5.99$ & $€ 6.49$ & $€ 5.99$ & $€ 6.49$ & $€ 5.49$ & $€ 5.99$ & $€ 5.49$ & $€ 5.99$ & $€ 4.99$ \\
\hline production & organic & organic & organic & organic & no label $=$ & no label $=$ & no label $=$ & no label $=$ & no label = \\
\hline method & label & label & label & label & conventional & conventional & conventional & conventional & conventional \\
\hline $\begin{array}{c}\text { information ol } \\
\text { fair trade } \\
\text { production }\end{array}$ & imprecise & precise & imprecise & precise & imprecise & precise & imprecise & precise & - \\
\hline label & Transfair & Transfair & fake & fake & Transfair & Transfair & fake & fake & Transfair \\
\hline
\end{tabular}

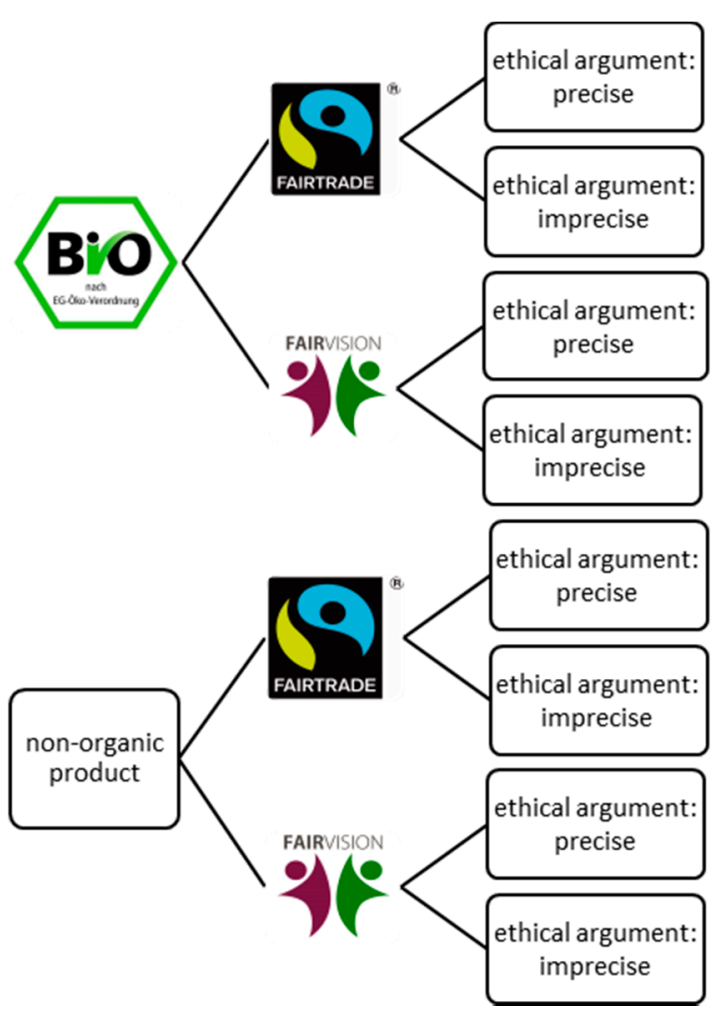

Figure 3. Schematic product design. Source: Authors' own illustration.

Each participant was confronted with a $7 \times 9$ matrix, which included nine different products endowed with seven different attributes: the price, information on the production method, a label and four different ethical attributes. Each set of products had one product that only contained information on the label (Transfair) and the price. All products and attributes randomly varied in order to avoid a bias due to 
common reading habits from the upper-left corner to the right bottom. For a schematic overview of the product design, see Table 1 which explains the design of the different products in more detail.

The final design of the products varied as to the information given on fair trade production. The attributes information on fair trade production, producer income, protection of children, trade relations and social projects on-site, could either be given in a precise manner, in an imprecise manner or no information was given at all. Since all product combinations could not be tested in the survey, two sets of matrices were created, resulting in 18 products tested in all. They were spread in two sets across two different, random groups of participants.

The IDM experiment was embedded into an additional written questionnaire that was computer-based as well. The questionnaire contained questions on consumers' motivations to purchase Fairtrade products, complementary information on participants' information search habits and their shopping behavior, as well as participants' socio-demographics. These data were collected to allow some additional analyses on the final purchase decision.

\subsection{Sample Description}

In all, 389 Fairtrade consumers took part in the survey. The socio-demographic data is displayed in Table 2. The results show that regarding age, gender and education, the participants do not totally represent the German average, since participants in this survey are more frequently between 18 to 44 years old, female and well educated.

Furthermore, participants' intensity of computer use was questioned and the results clearly indicated that the majority of participants were very experienced in using PCs: $85.3 \%$ of participants use the computer daily, and $87.4 \%$ shop online.

Results of participants' Fairtrade purchase habits show that the majority buys these products on a regular but infrequent basis: $47.0 \%$ reported that they purchase Fairtrade products once a month. Another significant group bought Fairtrade products rather intensively, about once per week. A total of $18.5 \%$ of participants chose Fairtrade only rarely, about once every three months. However, these results should be interpreted carefully since from organic product purchase research, it is known that consumers tend to overestimate their shopping frequency when it comes to the category of socially desired products [36].

Table 2. Socio-demographic data.

\begin{tabular}{ccccc}
\hline \multirow{2}{*}{ Variable } & Characteristics & \% of & AM & SD \\
\cline { 4 - 5 } & $18-25$ & participants & 40.0 & 12.1 \\
\hline \multirow{2}{*}{ Age $(\mathrm{n}=389)$} & $25-34$ & 11.1 & & \\
& $35-44$ & 31.6 & & \\
& $45-54$ & 16.7 & & \\
& $55-64$ & 25.7 & & \\
& $65-75$ & 13.1 & & \\
\hline \multirow{2}{*}{ Gender $(\mathrm{n}=389)$} & Male & 1.8 & & \\
& Female & 35.2 & & \\
\hline
\end{tabular}


Table 2. Cont.

\begin{tabular}{|c|c|c|c|c|}
\hline \multirow{2}{*}{ Variable } & \multirow{2}{*}{ Characteristics } & \multirow{2}{*}{$\begin{array}{c}\% \text { of } \\
\text { participants }\end{array}$} & $\mathbf{A M}$ & SD \\
\hline & & & 40.0 & 12.1 \\
\hline \multirow{5}{*}{ Education $(\mathrm{n}=389)$} & None & 0.0 & & \\
\hline & $\begin{array}{c}\text { Certificate of } \\
\text { secondary education }\end{array}$ & 1.3 & & \\
\hline & $\begin{array}{l}\text { General certificate of } \\
\text { secondary education }\end{array}$ & 10.3 & & \\
\hline & $\begin{array}{l}\text { University entrance } \\
\text { diploma }\end{array}$ & 27.5 & & \\
\hline & $\begin{array}{l}\text { University degree, } \\
\text { Polytechnic degree }\end{array}$ & 60.9 & & \\
\hline \multirow{2}{*}{ Employment $(\mathrm{n}=389)$} & Yes & 75.8 & & \\
\hline & No & 24.2 & & \\
\hline \multirow{9}{*}{ Household size $(n=389)$} & & 2.0 & \multirow{9}{*}{\multicolumn{2}{|c|}{1.2}} \\
\hline & 1 & 44.2 & & \\
\hline & 2 & 33.2 & & \\
\hline & 3 & 10.0 & & \\
\hline & 4 & 7.7 & & \\
\hline & 5 & 3.1 & & \\
\hline & 6 & 1.3 & & \\
\hline & 7 & 0.3 & & \\
\hline & 8 & 0.3 & & \\
\hline \multirow{11}{*}{$\begin{array}{l}\text { Net household income } \\
\qquad(\mathrm{n}=389)\end{array}$} & & $1963.6 *$ & \multirow{11}{*}{\multicolumn{2}{|c|}{$1201.7 *$}} \\
\hline & $<600 €$ & 10.8 & & \\
\hline & $600-€ 1200$ & 21.9 & & \\
\hline & $1200-€<1800$ & 13.6 & & \\
\hline & $1800-<€ 2400$ & 16.7 & & \\
\hline & $2400-<€ 3000$ & 8.5 & & \\
\hline & $3000-<€ 3600$ & 11.3 & & \\
\hline & $3600-€<4200$ & 6.9 & & \\
\hline & $4200-<€ 4800$ & 4.1 & & \\
\hline & $>€ 4800$ & 5.1 & & \\
\hline & Not specified & 1.0 & & \\
\hline
\end{tabular}

$\mathrm{AM}=$ Arithmetic mean; $\mathrm{SD}=$ Standard deviation. $*$ Classified mean value excluding the income group with no upper limit.

\section{Results}

\subsection{Extent of Information Search}

As each of the 63 information fields in both of the two matrix sets could be opened several times, there is a theoretically unlimited number of fields which could have been opened by the participants. However, participants retrieved on average 51.5 fields (including repeated clicks) before making the 
purchase decision. Obviously, some products have been equipped with attributes that were not favored by some participants (e.g., a high price) or some product attributes (e.g., social projects) were not of interest to a participant. However, the standard deviation is rather high (26.7) and the median is 48, which shows that there must be a substantial proportion of participants who searched for information quite intensively. In order to gain insight on what degree the bundle of information was used, the number of accessed fields without repeated field accessions must be examined. On average, each person opened about half of the matrix's fields (53.4\%; 33.6 fields absolute). Even though information search intensity was high, it can clearly be stated that not all the information was accessed, as often implied e.g. in Choice Experiments. On average, participants needed $4 \mathrm{~min} 43 \mathrm{~s}$ to make their purchase decisions. A relatively large standard deviation of $2 \mathrm{~min} 40 \mathrm{~s}$ and a lower median (4 min $10 \mathrm{~s}$ ) indicate that several participants took much more time in order to come to a purchase decision, $19 \mathrm{~min} 36 \mathrm{~s}$ in the maximum.

Due to the high standard deviation in the information search extent, a regression analysis was conducted to explain the factors leading to differences in information search extent. The hypothesis that age, household income, preferred retail store for Fairtrade purchases and education (independent variables-retrieved in the additional questionnaire) influence information search extent (dependent variable) was tested [32,34]. The dependent variable was operationalized by the number of opened fields which was recorded by the computer in the course of the IDM. However, this regression model could not explain the variations in information search extent $(\mathrm{F}=0.519 ; p=0.722)$. Presumably, involvement, which was not surveyed here, plays a major role in explaining information search extent, as shown earlier by Kardes et al. [37].

\subsection{Content of Information Search}

Results both from repeated and from first accession show that information on price, the Fairtrade label and production method are most important to Fairtrade consumers. Ethical attributes are less important. Only one ethical attribute, "protection of children" was amongst the four most important attributes in both measures. However, the results show that the two measures did not produce precisely the same results (see Figure 4). Since empty fields were often accessed repeatedly, results on repeatedly accessed information should be interpreted cautiously since repeated accession can also be due to forgetfulness rather than to the importance of the information.

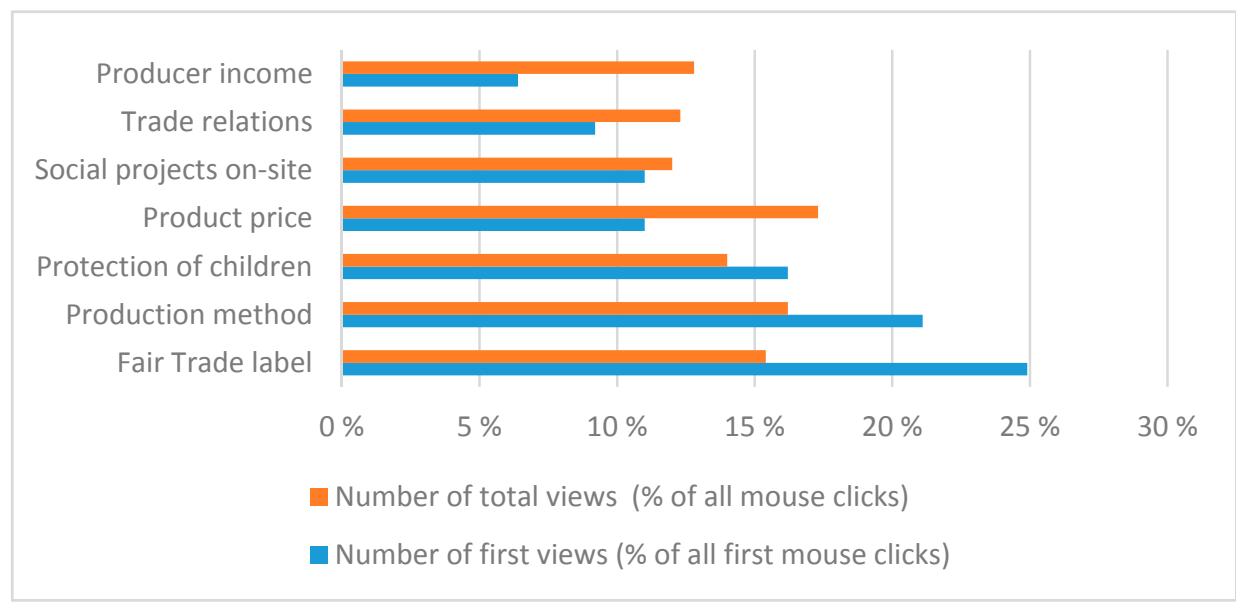

Figure 4. Most important ethical attributes. 
Results of the analysis of purchase decisions emphasize the importance of organic production, as, in most cases $(81.9 \%)$, a product with the eco-label was purchased. Regarding the price, in most cases (44.7\%), the product with the second highest price was chosen. As shown above, price seems to be an important selection criterion. However, a willingness to pay a price that is above the minimum price of the product with the lowest quality did exist. It was additionally shown that products with imprecise information on ethical attributes were strongly preferred over those with precise information. From a marketing perspective, it is highly relevant to explore what affects the information choice in order to adapt communication policy to consumers' needs. As this has not been done before for Fairtrade products, an explorative approach was chosen. Two logistic regression analyses were conducted with the aim to explore variables that could affect the purchase decision for a product with precise or imprecise ethical information. Model 1 tested whether the following variables could explain the purchase decision for a product with precise or imprecise attributes: search strategy as identified by tracking participants' search behavior, decision time, viewing time, number of opened fields, viewed attributes, viewed products (all as recorded in the course of the IDM). Model 2 tested the following independent variables: age, gender, household income, education, preferred retail store for Fairtrade purchases, perceived credibility of the tested labels, degree of agreement with the statement: "I feel sufficiently informed about Fairtrade" (all retrieved in the additional questionnaire), and the results of two factor analyses, "purchase motivation hedonism" and "purchase motivation pro-social behaviour". Results show that the probability of choosing a product characterized by imprecise ethical attributes fell with an increasing number of accessed information fields. Beyond that, the probability of choosing a product with imprecise ethical attributes rose the more the fake label was perceived as credible. That means that a product with imprecise attributes was preferred by consumers with a low knowledge of Fairtrade labels and was less preferred by consumers who conducted information search rather intensively. However, both variables only explain a small part of the total variance (Nagelkerke's $R^{2}: 0.030$ and 0.056 , respectively).

\subsection{Strategies of Information Search}

In $60.4 \%$ of cases, information search began in the upper-left corner of the matrix, which correlates with Western reading and writing habits. This effect could also be shown in preceding studies [28,32,33]. Table 3 offers an overview on the information search strategies applied by the Fairtrade coffee purchasers. Most information search strategies correlated with those in literature [25,38]. The Equal-Weights (EQW) strategy is characterized by an extensive information search. The strategy is compensatory and attribute based; a weighting of the information is also performed. Information search strategies classified here could also fall under the Weighted-Additive (WADD) strategy. In WADD, weightings are performed per attribute and not for the product as a whole. Due to the survey style applied here, a differentiation between the two information search strategies could not be made since weightings were not surveyed. Thus, WADD could not be found here. The Majority-of-Confirming-Decisions (MCD) strategy foresees pairwise comparisons of alternatives by attributes. The strategy is compensatory. Information search strategies falling under the Additive Differences (ADDIF) rule are integrated here as well, as ADDIF foresees further weighting which could not be traced here. Thus, ADDIF could not be found here, either. The Lexicographic (LEX) rule includes that the most important attribute is accessed first and is regarded in all alternatives. The alternative with the highest value for 
that attribute is chosen, while other alternatives are eliminated. When applying the Satisficing (SAT) heuristic, all alternatives are regarded consecutively. A minimum level for each attribute is set and needs to be reached. The first alternative that fulfils the minimum requirements for all information is chosen. The information search is performed alternative-wise. Elimination-by-Aspects (EBA) foresees minimum requirements regarding the information. Unlike SAT, the procedure is attribute-wise [25].

Table 3. Frequency of strategy application.

\begin{tabular}{lcc}
\hline \multicolumn{1}{c}{ Strategy } & Frequency (absolute) & Frequency in \% \\
\hline Attribute-wise comparison, total & 120 & 30.8 \\
Elimination-by-Aspects, total & 97 & 24.9 \\
Equal-Weights-Strategy, total & 18 & 4.6 \\
Lexicographic rule, total & 8 & 2.1 \\
Majority-of-Confirming-Decisions & 3 & 0.8 \\
Others & 8 & 2.1 \\
Random & 55 & 14.1 \\
Satisficing & 18 & 4.6 \\
All mixed strategies & 62 & 15.9 \\
Total & 389 & 100.0 \\
\hline
\end{tabular}

Furthermore, another strategy including the access of all information, albeit in an attribute-wise manner, was detected as well: the attribute-wise comparison (AWC). Here, all information was retrieved. Due to its analogies to the EQW strategy and the fact that the information search is not selective, it was supposed that the participants perform trade-offs; the strategy was thereby classified as compensatory.

Shifts in strategy application occurred. Such strategies were labeled as MIX strategies. A few search processes did not appear random, but could not be attached to any of the detected rules. These were marked as "others". A remarkable number of participants used search patterns that appeared randomly (RAND) and could not be assigned to any earlier described strategy nor could any other strategic approach be detected.

Regarding the frequency of strategy application, most often AWC and EBA strategies were chosen, followed by strategy mixing and random information search (Table 3). Summing up, the attribute-wise information search was applied more often than alternative-wise strategies. Compensatory and noncompensatory strategies were applied almost equally. Overall, strategies with a lower cognitive effort (attribute-wise strategies and non-compensatory strategies) were used predominantly.

When designing communication strategies, it is of great interest to gain insight on how consumers differ in their information search behavior in order to adjust the information presentation accordingly. Therefore, personal factors affecting the choice of the search strategy were analyzed in an exploratory manner. The information search strategies, being either compensatory or non-compensatory, were grouped accordingly. A stepwise regression analysis was chosen since it is suited for exploratory data analysis. The regression analysis contained the following independent variables: number of opened fields; decision time; age; gender; household income; education; and the results of two factor analyses, "purchase motivation hedonism" and "purchase motivation pro-social behavior". It could be shown that a compensatory strategy was more likely to be chosen as the number of accessed fields rose $(b=0.090$, 
$\exp (b)=1.09)$. Furthermore, the probability of choosing a compensatory strategy increased with a higher degree of education of the participant $(b=0.665$, $\exp (b)=1.94)$.

\section{Discussion}

\subsection{Extent of Information Search}

The IDM experiments have shown that the extent of information search when purchasing Fairtrade products goes beyond the verification of the Fairtrade feature via a label. This corresponds with results from de Pelsmacker et al. [15]. Specifically, world shop customers searched for information that went beyond the label, as was also shown by Aschemann-Witzel and Hamm [32].

\subsection{Content of Information Search}

Regarding the content of information search, the importance of Fairtrade labeling can be pointed out, as de Pelsmacker et al. [15,39] have done. However, a significant part of the participants confuse a fake label for an existing one, which shows that consumers have trouble identifying Fairtrade labels. Von Meyer-Höfer [40] came to a similar conclusion for German consumers and Fairtrade products as well. Consumers are clearly confused by the variety of different logos existing on the German food market and a low level of knowledge on the specifics of different labels.

Organic product quality played a major role in the purchase decision of Fairtrade products, which was also shown by Aschemann-Witzel and Hamm [32] and Langen [41]. Lehnert [10] detected a preference for Fairtrade products with organic standards, as well. Interestingly, world shop customers turned out to pay less attention to the organic criterion than other customers, in contradiction to earlier results of Bezencon and Blili [42] and Aschemann and Hamm [43].

Regarding the product price, the results coincide with those of de Pelsmacker et al. [39] who also found that price is one of the decisive Fairtrade purchase criteria. Some preceding studies stated that the premium price of Fairtrade products is a purchase obstacle $[3,44]$. Results of the present study do not support that. However, when comparing the results of the previously mentioned studies with those of the present study, it must be considered that here, only Fairtrade consumers were questioned, which implies that a principal willingness to pay an extra amount of money for the ethical attributes already existed, as Fairtrade coffee is normally offered at higher prices compared to "normal" coffee.

Results of studies by de Pelsmacker and Janssens [16] and by Carrigan and Attalla [45], which concluded that the quality of information was more important than the perceived quantity, cannot be supported by this study since the more detailed and precise "quality" information did not appear important to the participants. Instead, imprecise information was preferred. This goes hand in hand with the results of the analysis of the focus group discussions conducted prior to the IDM and showed that Fairtrade consumers' knowledge is rather superficial.

For consumers, the exact content of information on ethical attributes seems to be exchangeable. Except for the attribute "protection of children", clear information preferences could not be elaborated. Both sample groups purchased the same product preferentially, even though the ethical arguments differed. It can be discussed whether the bare fact that a product is equipped with additional information suffices for consumers. 
Interestingly, the attribute price gains much greater importance when surveyed indirectly via the IDM than via the questionnaire survey. This result is congruent with the results of Aschemann-Witzel and Hamm [32] as well as of Zander and Hamm [31]. The phenomenon can be explained by the fact that the social interaction between the interviewer and the interviewee is minimized in the IDM and therefore lowers the potential social desirability bias as well. As Zander and Hamm [31] mentioned, the connection between the IDM tasks and the derivation of individual behavior or attitudes is far less obvious. Therefore, the IDM is a suitable survey instrument when dealing with products that are subject to potentially biased answers due to social desirability.

\subsection{Strategies of Information Search}

As shown above, compensatory and non-compensatory strategies were used analogously. Similar results were found in another study on information search strategies regarding ethical products [33]. Ford et al. [46] explained that, generally, a large amount of retrieved information of the total information is characteristic for the application of compensatory strategies. What could indeed be shown was that the probability of choosing a compensatory strategy rises with the number of fields opened. Since compensatory strategies are cognitively more demanding than non-compensatory strategies, the fact that the probability of choosing a compensatory strategy rises with a higher degree of education is not surprising. However, in this study, compensatory and non-compensatory strategies were applied almost equally. A clear statement on the perceived complexity of the decision situation was not possible. Furthermore, the application of strategy mixing facilitates conclusions on the complexity of the decision task [47]. Because only about $15 \%$ of cases here applied more than one strategy, it can be stated that the majority of participants did not perceive the task as too complex. Compared to the survey on information search behavior for organic products by Zander and Hamm [33], a greater part of participants applied strategy mixing. On the one hand, this could be due to the smaller matrix $(7 \times 8)$ of Zander and Hamm [33] compared to this one $(7 \times 9)$ or due to the fact that consumers are more familiar with organic product purchase decisions than with Fairtrade purchase decisions. The relation between the application of WADD (or EQW) and EBA, which was observed by Payne et al. [25], could not be discovered here. It is likely that the possibility of marking important information fields with the "remember"-button was the participants' actual means of information reduction. Overall, participants could deal well with the amount of information provided.

Participants either applied cognitively more demanding strategies including a large quantity of information, or they applied easy rules of thumb, which are, according to Payne et al. [25], used when the quantity of information is perceived as great. Since about half of the detectable strategies were rules of thumb, one can conclude that about half of the participants did not perceive the information load as small. It must be noted that not only "rational" strategies including the processing of the whole amount of information were applied.

As in the surveys by Zander and Hamm [33] on organic food and by Weening and Marleveld [48] on refrigerators, attribute-based search predominated. Attribute-based search is deemed cognitively less demanding than alternative-based search [29]. Beyond that, information search is rather attribute oriented when searching takes place under time pressures [25]. One can suppose this was the case here, since the experiments took place in real shopping environments where consumers are under stronger 
time constraints than in laboratory experiments. Together with the insights on information search extent, one can conclude that despite the time pressure, Fairtrade consumers undertake an effort to gather prepurchase information on unknown Fairtrade products. Still, consumers tend to limit their effort, both as regards to the extent of information search as well as the cognitive involvement. It must be considered that the present study dealt with a product with a brand that was unknown to the consumers. It is assumed that the search effort, especially in the case of already known products but also in case of Fairtrade products under a well-known brand, might be lower.

As regards to search strategies, it must be said that not all strategies described in theory could be detected in this survey since weightings were not surveyed here. Thus, characteristics of some strategies could not be recorded [34]. Beyond that, one strategy which has not previously been described in literature was detected, the AWC strategy, which at the same time turned out to be difficult to interpret. In the case of AWC, all or almost all information was retrieved in an attribute-wise and strongly structured manner. The presence of the possibility to use the "remember"-button could have favored this strongly structured form of information search.

\section{Research Limitations and Further Research}

\subsection{Research Limitations}

The present results are limited to consumers of Fairtrade products in Germany. Since it was not possible to perform the interviews in front of discount shops, customers of discount shops which also offer Fairtrade coffee are underrepresented. Due to the fact that participants were introduced to the IDM matrix and, if needed, the handling of the PC and the mouse, they did not necessarily need computer skills. Participants received technical support if needed and were encouraged to participate regardless; the study is, therefore, not only limited to individuals with computer skills.

\subsection{Suggestions for Further Research}

Regarding the IDM methodology, this research has shown that the inclusion of the "remember" option should be further researched. The mostly very structured search manner in this study might be caused by the fact that the participants had the option of remembering interesting fields, which they checked again before making their purchase decision. The validity of repeated clicks as a means of measuring the importance of a piece of information in contrast to the first accessed information has not yet been analyzed. When using the IDM to analyze information search behavior, it would be helpful to gain further insight on this aspect.

Nowadays, IDM application has great visual potential due to new PC techniques which can be further developed. Therefore, product packages can be displayed or a virtual walk through a store can be simulated. Furthermore, a methodological comparison with the eye-tracking technique would be highly interesting. Consequently, the advantages of both the IDM method and eye-trackers could be combined. It would be highly interesting if further studies analyzed how search behavior differs according to the decision situation in order to explore the adaptability of information search techniques. In this regard, it is recommendable to survey the involvement relating to the surveyed object as well. 
This study did not analyze the importance of a brand. Possibly, a strong brand could have a comparable effect to a label in terms of creating credibility which could be researched in further studies.

\section{Conclusions}

Based on the aforementioned results, the information on Fairtrade specific issues should not go into too much detail since most consumers seem to feel overburdened by comprehensive and detailed information. Furthermore, marketers should remember that consumers are directly comparing single product attributes with competing products rather than considering the product as a whole, as the analysis of the search strategies has shown. This implies that the products need to be competitive on an attribute level and not only convincing in their entireties. There is a considerable number of Fairtrade consumers whose knowledge of Fairtrade labels as well as their ability to recognize an existing Fairtrade label is not deep. Therefore, further efforts should be made to improve consumers' ability to recognize Fairtrade labels, to increase knowledge on Fairtrade labeling, as well as to develop consumers' ability to differentiate between labels. As organic turned out to be a major purchase criterion, ongoing efforts to offer products which are both Fairtrade products as well as organic should also be increased.

From a consumer protection point of view, two results are critical. Consumers' low level of knowledge on Fairtrade labeling is alarming. The results of this survey have shown how easily consumers believe a fake label is real. In order to clear up consumer confusion about different labels on the market, the introduction of a governmentally protected label could be considered. Furthermore, an attempt should be made to increase consumers' knowledgeability on Fairtrade labeling, all the while taking into consideration consumer preference for imprecise information, which is also connected to a low information level. The preference for imprecise information is especially critical since it leaves consumers the "freedom to fantasize about Fairtrade" [49] (p. 372).

\section{Acknowledgments}

The authors wish to thank the three anonymous reviewers for their valuable comments which helped to significantly improve the text, and Anne Christopherson for the thorough language check.

\section{Author Contributions}

Rosa Schleenbecker conducted the empirical survey and analysis and drafted the manuscript. Ulrich Hamm developed the project idea and revised the manuscript and supervised the overall work. All authors read and approved the final manuscript.

\section{Conflicts of Interest}

The authors declare no conflict of interest.

\section{References}

1. Tallontire, A.; Rentsendorj, E.; Blowfield, M. Ethical Consumers and Ethical Trade: A Review of Current Literature; Policy Series 12; Natural Resource Institute Policy: Greenwich, UK, 2001. 
2. Auger, P.; Burke, P.; Devinney, T.M.; Louviere, J.J. What will consumers pay for social product features? J. Bus. Ethics 2003, 42, 281-304.

3. Uusitalo, O.; Oksanen, R. Ethical consumerism: A view from Finland. Int. J. Consum. Stud. 2004, 28, 214-221.

4. Carrigan, M.; Marinova, S.; Szmigin, I. Ethics and international marketing. Int. Market. Rev. 2005, $22,481-493$.

5. Shaw, D.; Grehan, E.; Shiu, E.; Hassan, L.; Thomson, J. An exploration of values in ethical consumer decision making. J. Consum. Behav. 2005, 4, 185-200.

6. Freestone, O.; McGoldrick, P. Motivations of the ethical consumer. J. Bus. Ethics. 2008, 79, 445-467.

7. Fairtrade International. What is Fairtrade? Available online: http://www.fairtrade.net/what-isfairtrade.html (accessed on 27 March 2015).

8. Low, W.; Davenport, E. Has the medium (roast) become the message? Int. Market. Rev. 2005, 22, 494-511.

9. Moore, G. The fair trade movement: parameters, issues and future research. J. Bus. Ethics 2004, 53, 73-86.

10. Lehnert, M. Präferenzanalyse ethischer Produkte: Eine verhaltenswissenschaftliche Analyse am Beispiel von Bio und Fairtrade; Markus Wiener Publishers: Hamburg, Germany, 2009.

11. Howard, P.H.; Jaffee, D. Tension between firm size and sustainability goals: Fair Trade coffee in the United States. Sustainability 2013, 5, 72-89.

12. Fairtrade International. Available online: http://de.statista.com/statistik/daten/studie/171401/ umfrage/ umsatz-mit-fairtrade-produkten-weltweit-seit-2004/ (accessed on 31 January 2015).

13. Dulleck, U.; Kershbamer, R.; Sutter, M. The economics of credence goods: An experiment of the role of liability, verifiability, reputation, and competition. Am. Econ. Rev. 2011, 101, 526-555.

14. Anderson, B.; Semadeni, M. Making Sense of a Competitor's Innovation: A Signalling Perspective on Whether to Imitate or Ignore the Competition. In Strategic Management in the 21st Century, 3rd ed.; Wilkinson, T., Kannan, V., Eds.; Praeger: Santa Barbara, CA, USA, 2013; Volume 2, pp. 3-22.

15. De Pelsmacker, P.; Janssens, W.; Sterckx, E. Mielants, C. Fair-trade Beliefs, Attitudes and Buying Behaviour of Belgian Consumers. Int. J. Nonprofit Volunt. Sect. Market. 2006, 1, 125-138.

16. De Pelsmacker, P.; Janssens, W. A model for Fair Trade Buying Behaviour: The Role of Perceived Quantity and Quality of Information and of Product-specific Attitudes. J. Bus. Ethics 2007, 75, 361-380.

17. Solomon, M.; Bamossy, G.; Askegaard, S.; Hogg, M. Consumer Behaviour: A European Perspective, 5th ed.; Prentice Hall: Upper Saddle River, NJ, USA, 2013.

18. Engel, J.; Blackwell, R.; Miniard, P. Consumer Behavior, 10th ed.; Thomson Press: Mason, OH, USA, 2006.

19. Kotler, P.; Keller, K. Marketing Management, 14th ed.; Prentice Hall: Upper Saddle River, NJ, USA, 2011

20. Payne, J.; Braunstein, M.; Carroll, J. Exploring Predecisional Behavior: An Alternative Approach to Decision Research. Organ. Behav. Hum. Perform. 1978, 22, 17-44.

21. Sauermann, H. Vocational choice: A Decision Making Perspective. J. Vocat. Behav. 2004, 66, 273-303. 
22. Ball, C. A Comparison of Single-Step and Multiple-Step Transition Analyses of Multiattribute Decision Strategies. Organ. Behav. Hum. Decis. Process. 1997, 69, 195-204.

23. Beatty, S.; Smith, S. External search effort: an investigation across several product categories. J. Consum. Res. 1987, 14, 83-95.

24. Assael, H. Consumer Behavior. A Strategic Approach; Houghton Mifflin Company: Boston, MA, USA, 2004.

25. Payne, J.W.; Bettman, J.R.; Johnson, E.J. The Adaptive Decision Maker; Cambridge University Press: Cambridge, UK, 1993.

26. Eysenck, M.; Keane, M. Cognitive Psychology: A Student's Handbook, 6th ed.; Taylor and Francis: Oxford, UK, 2010.

27. Lürssen, J. Produktwissen und Kaufentscheidung: Einbeziehung des Produktwissens bei der Analyse von Kaufentscheidungen mit der Informations-Display-Matrix; Lang: Frankfurt/Main, Germany, 1989.

28. Schopphoven, I. Messen von Entscheidungsqualität; Peter Lang: Frankfurt am Main, Germany, 1996.

29. Russo, J.; Dosher, A. Strategies for multiattribute binary choice. J. Exp. Psychol. Learn. Mem. Cogn. 1983, 9, 676-696.

30. Jacoby, J.; Chestnut, R.; Weigl, K.; Fisher, W. Description of a Process Methodology Research: Paradigm, and Pilot Investigation. Adv. Consum. Res. 1976, 3, 306-314.

31. Zander, K.; Hamm, U. Consumer Preferences for Additional Ethical Attributes of Organic Food. Food Qual. Prefer. 2010, 21, 495-503.

32. Aschemann-Witzel, J.; Hamm, U. Measuring Consumers' Information Acquisition and Decision Behavior with the Computer-Based Information-Display-Matrix. Methodology 2011, 7, 1-10.

33. Zander, K.; Hamm, U. Information Search Behaviour and its Determinants: The Case of Ethical Attributes of Organic Food. Int. J. Consum. Stud. 2012, 36, 307-316.

34. Kuß, A. Information und Kaufentscheidung: Methoden und Ergebnisse empirischer Konsumentenforschung; De Gruyter: Berlin, Germany, 1987.

35. Forum Fairer Handel. Der Faire Handel in Deutschland Zahlen, Entwicklungen und Trends für das Geschäftsjahr 2013. Available online: http://www.forum-fairer-handel.de/fileadmin/user_upload/ dateien/jpk/jpk_2014/factsheet_ffh_2013.pdf (accessed on 25 January 2015).

36. Niessen, J.; Hamm, U. Identifying the gap between stated and actual buying behaviour on organic products based on consumer panel data. In Cultivating the Future Based on Science, Proceedings of the second scientific conference of the International Society of Organic Agriculture Research, Bonn/Germany and Frick/Switzerland, Modena, Italy, 18-20 June 2008; Neuhoff, D., Halberg, N., Alföldi, T., Lockeretz, W., Thommen, A., Rasmussen, I.A., Hermansen, J., Vaarst, M., Lueck, L., Caporali, F., et al., Eds.; ISOFAR: Bonn, Germany, 2008, pp. 346-349.

37. Kardes, F.; Cronley, M.; Cline, T. Consumer Behaviour and Managerial Decision Making; South Wester Cengage Learning: Boston, MA, USA, 2010.

38. Kuß, A.; Tomczak, T. Käuferverhalten; Lucius und Lucius: Stuttgart, Germany, 2000.

39. De Pelsmacker, P.; Janssens, W.; Streckx, E.; Mielants, C. Consumer preferences for the marketing of ethically labelled coffee. Int. Market. Rev. 2005, 22, 512-530. 
40. Von Meyer-Höfer, M. Product Differentiation and Consumer Preferences for Sustainable Food. Available online: http://hdl.handle.net/11858/00-1735-0000-0022-5F5C-C (accessed on 25 January 2015).

41. Langen, N. Are ethical consumption and charitable giving substitutes or not? Insights into consumers' coffee choice. Food Qual. Prefer. 2011, 22, 412-421.

42. Bezencon, V.; Blili, S. Segmenting the market through the determinants of involvement: the case of fair trade. Psychol. Market. 2011, 28, 682-708.

43. Aschemann, J.; Hamm, U. Information acquisition behaviour of fair trade coffee consumers-A survey by means of an information display matrix. In Cultivating the Future Based on Science, Proceedings of the 2nd scientific conference of the International Society of Organic Agriculture Research, Modena, Italy, 18-20 June 2006; Neuhoff, D., Halberg, N., Alföldi,T., Lockeretz, W., Thommen, A., Rasmussen, I., Hermansen, J., Vaarst, M., Lueck, M., Caporali, F., et al., Eds.; ISOFAR: Bonn, Germany, 2008; pp. 338-341.

44. Basu, A.K.; Hicks, R.L. Label performance and the willingness to pay for Fair Trade coffee: A cross-national perspective. Int. J. Consum. Stud. 2008, 32, 470-478.

45. Carrigan, M. and Attalla, A. The myth of the ethical consumer-Do ethics matter in purchase behavior? J. Consum. Market. 2001, 18, 560-577.

46. Ford, J.; Schmitt, L.; Schechtman, S.; Hults, B.; Doherty, M. Process tracing methods: Contributions, problems, and neglected research questions. Organ. Behav. Hum. Decis. Process. 1989, 43, 75-117.

47. Jasper J.; Shapiro, J. Mouse trace: A better mousetrap for catching decision processes. Behav. Res. Meth. Instrum. Comput. 2002, 34, 364-374.

48. Weening, M.; Marleveld, M. The impact of time constraint on information search strategies in complex choice tasks. J. Econ. Psych. 2002, 23, 689-702.

49. Griffiths, P. Ethical objections to fairtrade. J. Bus. Ethics 2012, 105, 357-373.

(C) 2015 by the authors; licensee MDPI, Basel, Switzerland. This article is an open access article distributed under the terms and conditions of the Creative Commons Attribution license (http://creativecommons.org/licenses/by/4.0/). 